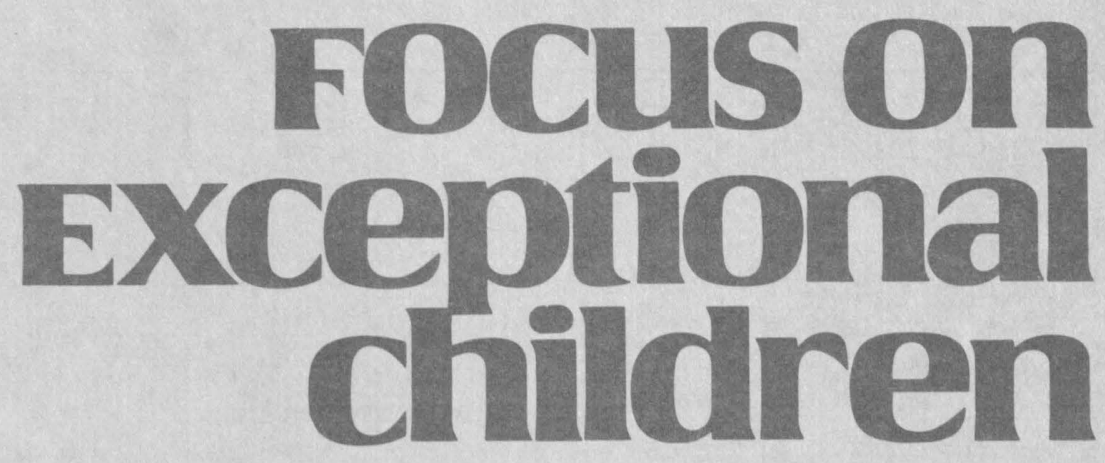

\title{
Effective Strategies For Involving Families in Intervention Efforts
}

\author{
Pam Winton
}

A focus on parents in the last two decades, and on families most recently, has been a notable and consistent trend within the field of special education. Although continuity is apparent in the sense of the overall emphasis, the treatment of and attitudes toward families have undergone a series of shifts over time. These changes and how they have affected parent involvement policy and practice have been described in some detail elsewhere (see Turnbull \& Winton, 1984). Nevertheless, an examination of the most recent shift in thinking on parent involvement - one in which all of us in the field are a part-can provide the framework for applying effective strategies in working with families.

\section{PARENT INVOLVEMENT IN EARLY INTERVENTION}

The importance of involving parents of handicapped children in early intervention efforts was a recurrent and undisputed theme of the 1970s. Research clearly demonstrated parents' significant contribution to child development. The major assumption underlying efforts to involve parents was that this contribution could be enhanced by teaching parents (parents as learners) how to better manage and teach (parents as teachers) their own children. Professionals' efforts to improve services for parents primarily focused on ways to increase parent participation in activities of this type and on development of various parent training curricula and materials. The search for a model parent involvement program that could be disseminated on a nationwide basis was an elusive goal that some sought.

The reason for involving parents was to enhance child outcome. This was so in spite of ample evidence demonstrating that parents of handicapped children had needs of their own. They were shown to suffer from depression, marital discord, and chronic sorrow, among other things. Within special education the predominant approach to dealing with this issue was to provide parent support groups. But the parent involvement trend of the 1970s did not incorporate an understanding of how parent needs might interact with child needs or interfere or be at cross purposes with the professional desire to enlist parent support for the educational process.

Dr. Winton is affiliated with the Frank Porter Graham Child Development Center, a Division of the Child Development Research Institute, University of North Carolina at Chapel Hill. 
As pointed out in a previous review article (Winton, 1986), this approach to parents was in keeping with special education traditions. The role of special educators within the service delivery system has been to promote child progress; involving parents as a means for reaching this end was not unreasonable. The development of programs and materials for training teachers has been another traditional domain for special educators; extending these efforts in the direction of parents was a logical step.

Research documented the success of many of these efforts in terms of particular child behaviors and skills (Baker, 1984). But rarely, if ever, did researchers evaluate programs in terms of their success at improving parent outcomes or meeting parents' individual needs. Additionally, in spite of professionals' efforts to devise exemplary parent involvement programs and to increase parent participation in those programs, evidence showed participation to be low (Rosenberg, Reppucci, \& Linney, 1983) and attrition high (KopperRoland, 1986). This suggested that the needs of parents were not universally being met.

\section{Focus on
Exceptional
children}

FOCUS ON EXCEPTIONAL CHILDREN (ISSN0015-511X) (USPS 203-360) is published monthly except June, July, and August as a service to teachers, special educators, curriculum specialists, administrators, and those concerned with the special education of exceptional children. This journal is abstracted and indexed in Exceptional Child Education Resources, and is also available in microform from Xerox University Microfilm. Ann Arbor, Michigan. Subscription rates, $\$ 24.00$ per year. Copyright $\odot 1986$, Love Publishing Company. All rights reserved. Reproduction in whole or part without written permission is prohibited. Printed in the United States of America. Second class postage is paid at Denver, Colorado.

POSTMASTER: Send address changes to:

Love Publishing Company
Executive and Editorial Office
1777 South Bellaire Street
Denver, Colorado 80222
Telephone (303) $757-2579$
EDITORIAL BOARD

EDITORIAL BOARD

Edward L. Meyen

University of Kansas

Richard J. Whelan

University of Kansas Medical Center

Stanley F. Love Publisher
Glenn A. Vergason Georgia State University

\section{Carolyn Acheson} Senior Editor

\section{PARENT INVOLVEMENT AS MANDATED BY PL 94-142}

Because of the emphasis during this period on early intervention, most of the parent involvement efforts and materials focused on younger handicapped children. Passage of PL 94-142 (The Education for All Handicapped Children Act) in 1975 broadened the focus on parents in terms of age of child and parent roles. For the first time, parents of all school-aged children (the laws of each state determine the definition of "school-aged") were authorized to be involved in their child's education. (For a complete description of how PL 94-142 affects handicapped children and their families, see Turnbull \& Turnbull, 1986.)

An underlying assumption of this legislation was that the best way to ensure that each handicapped child would receive an appropriate education was to involve those who know him or her best and have the child's best interests at heart (the parents) in formulation of an individualized education program (IEP). Again, the primary beneficiary of this form of parent involvement was the child.

The importance of this legislation for families of handicapped children cannot be overemphasized. One contribution was the relief from the stress of never knowing what to expect from the educational system. Now an appropriate education was mandated by law. A quote from Lynn Isbell (1983) illustrates the contrast between pre- and post-PL 94142:

[Parents spent] years running their own day care centers, begging for about-to-be-torn-down buildings from cities and counties, [holding] raffles and cake sales, [fighting] ever higher tuition costs, and [having] no transportation except car pools. This was the educational system for handicapped children of school age. Parents went through all of the hardships above, and more, and all for programs that were constantly running on a shoestring, about to go under, about to be evicted and quite often not much more than a kind of group babysitting anyway. For many years this was considered good enough for children who were demonstrating daily that they did have the ability to learn. (p.76)

Another contribution was that the emphasis on parents as partners in decision making was a departure from the traditional parent-professional relationship and set the stage for even greater changes in treatment of and attitudes toward parents. An examination of parent participation in the IEP process, however, revealed results that were surprising to many. A review of this research indicated that parents played a passive role rather than the active one underlying the policy intent of the law (Turnbull \& Winton, 1984).

Why did the well-meant efforts of professionals to involve parents have such mixed results? Because of the professional 
interest in parent perspectives, predominately generated because the law now legitimized and in fact mandated that these perspectives be considered, research with parents helped answer this question.

Anecdotal evidence from an interview study (Winton \& Turnbull, 1981) suggested that involvement with the child and involvement with the child's educational program were two very different issues for parents, and that at times the two might be incompatible. For example, a highly motivated and involved parent might decide to forego home therapy exercises with her child if they began to interfere with mutual parent-child enjoyment.

This study also illustrated that the needs of the handicapped child might conflict with the needs of other family members. For example, intense parent involvement in handicapped-related activities might substantially reduce the amount of time for other children in the family. In addition, parents described how activities such as parent support groups, which they had valued at one point in time, were not of interest at later points. In fact, some parents stated that at certain times they did not want any role in their child's education - they wanted a break.

These findings were supported and mirrored in other anecdotal accounts and by some clinicians working in the field. Doernberg (1978), for instance, cautioned that her experience suggested that intervention with parents had as much potential for harm as it did for good if it were not based on careful assessment of individual families' needs and perspectives.

Overall, the 1980 s have been accompanied by a growing awareness that parent involvement policy and practice require reevaluation (Foster, Berger, \& McLean, 1981; Turnbull \& Turnbull, 1982). Basic assumptions of the 1970 s - that efforts with parents should be directed toward increasing their participation in decision-making and teaching roles and that this is the most effective way to enhance child outcome-are being challenged. There is recognition that involving parents raises complicated issues and problems that are outside of the traditional realm of special education expertise and that if programs for parents are going to be effective, these issues and problems must be understood so that meaningful individualized programs can be developed. This awareness led special educators to look to the work of family therapists and family sociologists for theories and assumptions that might be useful in understanding and working with parents of handicapped children. This has proven to be a fruitful and exciting venture.

\section{PRINCIPLES SHAPING NEW DIRECTIONS FOR INVOLVING FAMILIES}

\section{The Child is Part of a System}

The concept of the child as an interdependent part of a larger system is perhaps the cornerstone of the shift in approaches with families of handicapped children. This basic concept, which is the core of systems theory, was advanced in the educational literature in the 1970 s by Bronfenbrenner $(1976,1977)$ in his ecological model of human development. Only recently, however, has the concept directly shaped intervention with parents.

Bronfenbrenner conceptualized the individual as residing within nested concentric structures that influence each other in an interdependent fashion. He proposed four such structures: the microsystem (which includes the relationships between family and school); the mesosystem (which includes the relationships between family and school); the exosystem (which includes the family social support network); and the macrosystem (which includes the legal system and social policies and public attitudes that affect handicapped persons). Using Bronfenbrenner's model as a framework, the handicapped child is seen as part of a dynamic system of parents, siblings, grandparents, extended family, friends, neighbors, community, culture, and country.

\section{ฟimplications for Practice}

This concept of interdependency within a larger system clearly challenges intervention efforts that do not acknowledge and take into account the various contexts in which the child resides. The individualizing done for children in the 1970s was based on internal characteristics of the child, such as learning style. If the multiple influential factors outlined by Bronfenbrenner are considered, the notion of individualizing for the child is considerably broadened. When special educators expanded their efforts in the 1970s to include parents, their goal had not been to better understand this important context in the child's life. Rather, it was to enlist parent aid in reaching narrowly defined child outcomes.

What has changed is that the saliency and importance of parents has been redefined. Rather than being viewed solely as additional manpower or contributors to child development, parents now are being appreciated as members of a significant and mediating social system that must be understood, and whose contribution to understanding the contexts 
influencing and being influenced by the child is critical in formulating meaningful intervention goals.

The decision-making role mandated by law but so passively acted on in practice has been redefined. Before, parents were seen as important because their understanding of their child's needs could be useful in determining the most appropriate education for the child. Now, an understanding of the "family context"- meaning such things as family membership characteristics, socioeconomic status (SES), cultural style, religious affiliations, social support network, ideological beliefs, and interrelationships of family members-are considered important factors in and of themselves (see Winton, 1986, or Turnbull \& Turnbull, 1986, for more complete treatment of each of these family factors). In fact, some professionals now believe that special educators must make every effort to understand these aspects of every family's situation in order for professionals and families to collaboratively formulate intervention goals (Bailey, in press; Turnbull \& Turnbull, 1986).

This change in thinking definitely represents a step beyond the decision-making role described in the IEP research in which parent input was sought on child-oriented issues. As evidenced by the terminology used in the literature, the trend is moving away from discussions of "parent involvement" and moving toward "family-focused interventions." With the family being bracketed as the significant system with which efforts for handicapped children are being conducted, consideration of theories and models of family functioning is becoming increasingly important. The next four principles describe conceptualizations related to understanding the family as a system.

\section{The Family is Composed of Subsystems}

Special educators have begun to look at families as being made up of subsystems having reciprocal effects on one another (Stoneman \& Brody, 1984; Turnbull \& Turnbull, 1986). Because of the interrelatedness of family members through their memberships in different subsystems (parentchild subsystem, sibling subsystem, grandparent-grandchild subsystem, and others), change in any one part of the system or to any one person in the family affects all other family members.

An important aspect of the principle of family subsystems is the idea that interactions between subsystems are regulated and maintained by certain patterns. These patterns change as a function of development and external demands. Problems with interactions between subsystems and with adapting to change seem to be associated with dysfunctional families (Minuchin, 1985).

\section{گ̇Implications for Practice}

The persistent and ever changing demands of parenting a handicapped child require numerous adaptations on the part of family systems. Unfortunately, however, an understanding of family subsystems has not played a major part in efforts to help families. Typically, activities for parents have focused on the mother and on mother-child dyads. Now we are recognizing that the needs, perceptions, and contributions of fathers (Parke, 1986), siblings (Simeonsson \& Bailey, 1986), and grandparents (Gabel \& Kotsch, 1981) are important factors to consider. We do not yet know what type(s) of direct intervention might be most useful for these family members, nor do we know the specific effects of excluding certain family members from intervention. We do know that being sensitive to their needs, and appreciating that intervention is affecting them-regardless of whether they are directly engaged - is important.

For instance, a typical intervention approach is to involve the mother in a home therapy program with her child. Although this might result in positive gains for the child, from a family systems perspective it might unwittingly do more harm than good by overstrengthening the mother-child subsystem and weakening the spouse subsystem. The work of Foster and Berger illustrates an approach to intervention that is sensitive to these issues (Berger, 1986; Foster \& Berger, 1979; Foster, Berger, \& McLean, 1981). They noted that even though the education content of a family goal may have a traditional special education focus, the dyad selected to implement the goal may change as a result of understanding family therapy assumptions.

\section{Family Members Perform Different Roles}

Another way of conceptualizing the family as a social system is in terms of the various roles performed by individual family members that ensure effective performance of various tasks (Goldenberg \& Goldenberg, 1980; Rollins \& Galligan, 1978). Nine major tasks or family functions have been described in the literature (Turnbull, Summers, \& Brotherson, 1984): economic, physical, guidance, education, vocational, rest and recuperation, socialization, selfdefinition, and affection.

One line of special education research in this regard has looked at differences in domestic tasks performed by mothers and fathers in families of handicapped and nonhandicapped 
children (Gallagher, Cross, \& Scharfman, 1981; Gallagher, Scharfman, \& Bristol, 1984). This research indicated that allocation of family tasks was similar in the two types of families and rather closely followed the traditional family patterns of mother as homemaker and father as provider. Of particular interest was the strong agreement found between husbands and wives on the division of domestic tasks in the family.

The ways in which family roles and family subsystems interact are illustrated by the research of Kazak (Kazak, 1986; Kazak \& Marvin, 1984). Using different measures with a different population of handicapped children than did Gallagher, she found evidence of differences between families of handicapped and nonhandicapped children in terms of parenting roles.

The conclusions Kazak reached from her data were that parents of handicapped children were even more rigidly traditional in their enactment of roles then were parents of nonhandicapped children. Mothers functioned almost solely in day-to-day parenting tasks. Fathers were very uninvolved in this domain but highly involved in employment related tasks. Because her research indicated that marital satisfaction in the families of handicapped children with this pattern was high, Kazak concluded that rather than being a dysfunctional pattern, it may be an adaptive way for families to deal with the stress of a handicapped child. A father who is uninvolved in the child-parent subsystem may be highly involved in the spouse subsystem, and within the context of the financial demands on the family system brought about by the child's handicap, this may be an adaptive coping machanism.

\section{预Implications for Practice}

Viewing the family from this perspective of roles highlights the importance of broadening the focus beyond the purely educational one that special educators traditionally have emphasized. Research clearly demonstrates that families of handicapped children have needs in many areassuch as help with physical caretaking, respite, financial strain, parent or sibling counseling, and others. Overlooking the multiple demands on a family by focusing on only one function not only might result in noncompliance with family and child goals but also might create guilt in the family for attending to other important functions, or even neglect of certain important aspects of their family life, such as recreation and play.

Kazak's research makes the point clearly that no cookbook approaches are forthcoming. Automatically assuming that overinvolvement on the mother's part is dysfunctional, with- out an understanding of the context in which the overinvolvement is taking place, might lead to disastrous results. When planning intervention, respect for the family's definition of each member's roles and the context in which they are performed is important.

\section{The Family Has a Life Cycle}

Another concept recently receiving attention from special educators is the notion of family life cycle. Variously called family passages, family transitions, and family life events, this idea recognizes that families, like individuals, progress through developmental phases. Some phases are predictable: couple, child bearing (families with preschoolers), school age, adolescence, post-parental, and aging (Olson, McCubbin, Barnes, Larsen, Muxen, \& Wilson, 1983). Other transition events are unpredictable, such as changing jobs, moving to a new location, or giving birth to a handicapped child. In either case all developmental transitions disrupt established family routines and patterns; and this change from a familiar to an unknown state is accompanied by anxiety and a certain degree of stress (Haley, 1973; Hansen \& Johnson, 1979).

Because of the interrelatedness of family members, a transition event that might seem to affect only one family member or subgroup in reality has an impact on the entire family system (Bronfenbrenner, 1976; McCubbin \& Patterson, 1983). At these transition points families adapt by reorganizing and creating new routines. This reorganization entails changes within the family, such as renegotiation of domestic tasks, reallocation of resources, and resetting of functional priorities, and changes between the family and outside agencies, such as hospitals, schools, and job places. These transition points are frequently a time when family problems arise (Berger, 1986; Haley, 1980).

For families of handicapped children, additional stresses associated with transitions are likely. Wikler (1981) identified 10 critical events-some relating to "missed" developmental milestones (e.g., child not walking at the appropriate time) and some to the disability itself (e.g., younger sibling's skill development surpassing delayed child's) - that are likely to increase stress for families of handicapped children. These unexpected events are particularly stressful for several reasons. When expected critical events, such as the birth of a baby or the death of an aging parent, occur, families can benefit from the wisdom of society in knowing how to deal with the associated stress. But with unexpected critical events, families or their support systems seldom have any 
guidelines on how to react. The "comfort in sharing" (McCubbin \& Figley, 1983) and the "anticipatory socialization" or contact that allows identification with persons already functioning in the role into which a person has just been thrust (Suelzle \& Keenan, 1981) - two concepts identified as being helpful in coping with crisis-are not readily available when famiies face unexpected events.

In the case of birth of a handicapped child, friends and family usually are at a loss as to how to react. Families may find themselves trying to deal with the discomfort of their support system at the same time that they themselves are in need of tremendous support. In addition, the family most likely does not know anyone who can share the experience or provide a role model to help in knowing how to cope.

\section{Implications for Practice}

The concept of family life development clearly defines the need for intervention to respond to the changing and dynamic nature of the family. The concept also emphasizes the importance of attending to transition events- not only those that are educational in nature, such as the child moving from one program to another, but also those that occur in other domains. (See Lamb, 1986, and Turnbull \& Turnbull, 1986 , for a more complete listing and discussion of various critical events associated with the life cycle of families having a handicapped family member.)

\section{THE INTERACTION OF FAMILY CONCEPTS}

The following descriptions of certain critical events associated with three phases of family life development (families with young children, families with school-aged children, and families with young adults) illustrate how the concepts of family subsystems, family roles, and family life cycles interact.

\section{Families With a Handicapped Infant or Preschooler}

Research suggests that the first stage of parenting (the preschool years) is the most intense. Parents experience much joy but also much frustration related to parenting (Hoffman \& Manis, 1978). For parents of handicapped children, the likelihood of frustration is even greater. Potentially problematic is the critical area of parent-child interaction. Physical and temperamental characteristics sometimes associated with handicapped infants (e.g., abnormal appear- ance, fussiness, limited ability to share in social exchanges, delays in smiling) and environmental factors associated with the handicap (e.g., frequent hospitalizations and separations from family and painful medical procedures) all can contribute to problems in the development of parent-child attachment.

An appreciation of the risks to early bonding in the case of premature or handicapped infants, for example, has influenced the direction of certain medical interventions. In response to this awareness, recent innovations in medical practices in neonatal intensive care nurseries have been implemented to facilitate bonding (see Kaiser \& Hayden, 1984, for a review). Another example of intervention that is sensitive to the mutual effects of parent-child interaction is the Parent-Child Reciprocity Project at the Frank Porter Graham Child Development Center. The overall goal of the project is to help families develop skills at "reading" cues their child elicits and to recognize progress and change so subtle that it may not be readily apparent to families.

Another event associated with the early years is the evaluation and diagnostic procedure leading up to identification of a handicapping condition. Much has been written about this process, and one overriding conclusion that must be drawn is that this is an emotional and critical point in the development of the parent-professional relationship. Guidelines are available for parents (Winton, Turnbull, \& Blacher, 1984) and for professionals (Olson \& Kroth, 1986; Turnbull \& Turnbull, 1986) on ways to facilitate this information-sharing process. Less information is available, however, to assist parents with the difficult task of informing siblings, grandparents, extended family, and friends about the diagnosis and identification of a handicapping condition.

Seeking and choosing intervention is another transition event for families during this phase. As mentioned earlier, intervention has the potential for both alleviating and creating stress (Doernberg, 1978; Cirillo \& Sorrentino, 1986). Locating appropriate services for younger handicapped children may be difficult for a number of reasons. Laws mandating services vary from state to state, and services vary from community to community within states. Research suggests that even when services do exist, parents must seek them out on their own; what seems to be lacking is an adequate communication system between and among parents, professionals, and agencies (Becker, Bender, \& Kawabe, 1980; Rosenberg, Reppucci \& Linney, 1983; Suelzle \& Keenan, 1981; Winton, 1986). One mother made these comments about her search for a preschool program: 
I am aware of the tremendous struggles that families in this sophisticated and liberal community have in finding help for their impaired children. Often excellent programs exist, but parents and professionals are unaware of them. To a great extent this is because there is a lack of coordinated services, a lack of publicity about services that exist, and uncertain funding - a program may be here today and gone tomorrow. I am appalled by the lack of knowledge about programs that I see among professionals who counsel parents.

To take our own example, even though our child was diagnosed soon after birth as 1) cerebral palsied, 2) retarded, 3) functionally blind, and 4) hydrocephalic, we were never directed by the followup clinic staff, the pediatrician, numerous psychologists, our ophthalmologist, or the neurosurgeon to any program that could help us or our son. Every school and preschool our son has attended has been through a chance discovery on our part. He currently attends a wonderful school in San Francisco that I found through a woman I met in a cooking class.

Our experiences are not unique. During a meeting at my son's preschool attended by close to 50 parents, almost every set of parents expressed anger that they had found out about the school through word of mouth, not from a professional. (Winton, Turnbull, \& Blacher, 1984, p. xii)

Evidence suggests that families whose young child's handicap is ambiguous or difficult to diagnose or label find the search for services even more stressful (Bernheimer, Young, \& Winton, 1983). Parents in this situation often are in the position of looking for a program without really knowing what approach to treatment would be best. Based on research on general family stress, McCubbin, Cauble, and Patterson (1982) made the point that ambiguity of a stressor may increase family stress because of the possibilities for disagreement about how to proceed.

In addition to trying to understand how laws, federal and state, affect what is available and then trying to find these services in the local community, parents during this phase also may be faced with broader philosophical issues, such as mainstreamed versus specialized placement or home care versus day care. Clearly this is a time when families can benefit from working with an objective, informed professional who can help them with the philosophical and practical issues associated with seeking appropriate intervention.

Once services or programs have been selected, another array of critical events faces families. From a theoretical perspective involvement with an intervention program means that families must redefine their boundaries to incorporate professionals with whom a relationship must be formed. As mentioned earlier, this transition can be stressful (Boss \& Greenberg, 1984). Research with families of normally developing young children making a transition to kindergarten (Klein \& Ross, 1958) illustrated specifically the kinds of issues asociated with the stress. Parents indicated that they worried about their child's ability to adjust to the new situation, felt a sense of loss associated with their child's entering school, had value conflicts (between differing school values and home values), and experienced tension in regard to the adjustment to sharing authority with their child's teacher.

Research by Granger, cited by Wright, Granger, and Sameroff (1984), suggested ways that value differences between parents and professionals might increase stress in a population with handicapped members. Their study indicated that the social support provided by an intervention program reduced stress in mothers with a sophisticated understanding of child development. For mothers whose understanding of child development was unsophisticated (and, therefore, different from the professionals with whom she was working), however, the intervention was associated with greater stress. Wright et al. (1984) speculated that the new information provided by the interventionists so challenged the perspectives of these mothers that confusion and anxiety, rather than support, resulted.

Cirillo and Sorrentino (1986) described potentially devastating results when education or health services are planned without regard to ways in which they may disrupt family relationships. By being too easily available, the therapist may take over the role of spouse to a mother who is cooperating with rehabilitation, or may disrupt everyday family life by exacting intensive involvement with a home therapy program.

\section{Families With a School-Aged Child}

As the handicapped child grows older, research suggests, fewer resources are available and social isolation in the community occurs (Suelzle \& Keenan, 1981). Reactions of peers to handicapped children become more salient at this point, and parents must deal with issues such as social stigma, the child's need for recreational outlets, budding sexuality, and self-concept. Issues facing parents include participation in IEP conferences, increased parental awareness of their handicapped child's limitations, and the possible beginnings of parental burnout. The elementary years also may be the first time that siblings are exposed to the handicapped family member in a daily peer situation. This may subject siblings to teasing and ridicule, directed toward them or toward their sibling, or may put them in a position of having to explain the handicapping condition to others. Professionals should be prepared to deal sensitively with these issues. Programs have been designed to help families with their handicapped child's transition from preschool to public school (Blair-Thomas, Wilson, \& Clark-Guida, 1985; 
Fowler \& Turnbull, 1984; Gallagher, Maddox, \& Edgar, 1984).

\section{Families With a Handicapped Young Adult}

Perhaps the most neglected phase in familiy life development, in terms of assistance to families with a handicapped family member, is when the family member reaches adult status. Suddenly the safeguards and services mandated by law are no longer available, and many families feel that the services provided to their child to this point have not prepared the child for the transition to adulthood. Issues facing families at this juncture include consideration of an independent living situation, such as a group home; responsibilities within the family for long-term care and guardianship; long-term social development and activities related to dating, marriage, sexuality, and birth control; and vocational placement and employability.

These are all complicated and thought provoking issues; yet research indicates that many families simply do not discuss these matters (Turnbull \& Brotherson, 1984). Decision making is often not systematic. In fact, individual family members may have very different ideas about these issues, their responsibilities in regard to the handicapped family member, and their perceptions of what other family members think.

A critical role for professionals is to provide systematic family intervention to assist with transition points. Model programs that do approach transitions from a family systems perspective have been developed. One of these, at the University of Kansas, is designed to help relevant family members and their support network problem-solve together to develop appropriate future plans for the exceptional adult (Turnbull, Brotherson, Bruininks, et al., 1984).

\section{A MODEL FOR WORKING WITH FAMILIES}

Acceptance of the principles described in this article, and their applicability to working with families of handicapped children, clearly calls for an individualized approach. The idea of an "individualized family plan" is not new (Karnes \& Zehrbach, 1975; Turnbull \& Turnbull, 1982); but a number of unresolved and vexing issues related to family assessment, evaluation, and implementation have contributed to the difficulties of translating theory into practice (see Winton, 1986, for more thorough treatment of these issues).
The first step in developing a practical, individualized model for working with families is to organize the numerous family variables considered important into a framework that is useful for predicting successful family outcome. One such framework is Hill's (1958) ABCX model, and McCubbin and Patterson's (1983) Double ABCX extension of Hill's model. According to Hill's basic model, a family's vulnerability to crisis depends on the interaction of the crisis event (A factor) with existing resources (B factor) and with family perceptions ( $\mathrm{C}$ factor).

A model for family-focused intervention with young handicapped children has been developed (Bailey et al., 1986a, 1986b). It incorporates assumptions from family systems theory into the $\mathrm{ABCX}$ model framework, in which a family's strengths and resources, as well as the family's definitions and perspectives on critical variables, are considered integral parts of setting family goals. The important elements of this model, which could be incorporated into intervention with families at any life-cycle phase, are family assessment, family goal setting, and implementation.

\section{Family Assessment}

Five primary domains are considered important for assessment:

1. Child variables relevant to family functioning

2. Family needs for support, information, training

3. Parent-child interaction

4. Parental perspectives on child rearing

5. Critical events in the family's current life cycle.

The importance of using multi-method strategies (direct observations, self-rating and self-report by parents, "objective" ratings by professionals, and focused family interviews) for gathering family assessment information cannot be overemphasized. Without a thorough understanding of the family's definition of its situation, efforts to intervene will likely fail.

\section{Family Goal Setting}

A critical question in terms of family intervention is: Who should determine family goals? Traditionally this has been the domain of special educators, not families. Research by Cadman, Shurvell, Davies, and Bradfield (1984) has suggested that compliance with professionals' recommendations for handicapped children was not what professionals would hope for (slightly in excess of $25 \%$ of the recommen- 
dations were not followed) even though the parents in the study were involved in the decision-making process. The reasons that parents stated for noncompliance related to parents' attitudes and beliefs about the recommendations. These factors were more important than measured characteristics of the child, the parent, or the type of recommendation made.

Research reported in the business literature has indicated that participatory goal setting was associated with greater success at reaching goals (Latham \& Locke, 1979). One might speculate that the same involvement would be important in setting family goals. In fact, a tactic described in the family therapy literature as important in helping families is to assume that the most adequate solutions to a family's problems lie within the family's own definition of reality (Berger, 1986).

The specific mechanism for family goal setting described by Bailey et al. (1986a, 1986b) is the family-focused interview. This is a process in which the interventionist uses previous assessment information to help structure the interview, while remaining open to issues that the family believes are relevant. An important element of collaborative family goal setting is to negotiate values and priorities, especially when family members disagree with each other or when interventionists and family members hold different values. This is a complicated issue with no simple answers. Articles by Bailey (in press) and Aponte (1985), which include sections on negotiating professional and family values, emphasize the underlying importance of professionals' understanding their own values and their ability to communicate acceptance and respect for the family and its values.

\section{Implementation}

The success of any intervention model rests in the hands of those who implement it. For that reason, a critical factor is the skill and knowledge of the professionals working with families. The family approach being described calls for a fairly substantial change in the nature of the special educator's role. It calls for knowledge and skill in areas such as family systems theory, group dynamics, communication and interviewing, and family assessment.

By suggesting that special educators identify a broad range of family needs and definitions of problems, the model may seem to imply that special educators will be able to provide a much larger array of services to families. That does not necessarily have to be the case. What is implied by the broadened definition of intervention is that the special educator will have to function in a case manager's role, whose responsibilities are to be familiar with a wide range of community resources and to be able to provide linkages for families as they seek information, services, and support.

This does not suggest that special educators should function as family therapists, even though, in the course of assessing or interviewing families, serious dysfunctional patterns may be revealed. What it does suggest is that special educators should have (a) the skills to help families identify their own needs for therapy and (b) the knowledge of community resources that offer and can provide the direct services needed. Also important is special educators' recognition of families' existing support systems and strengths so that those resources can be enhanced. The ultimate goal for the special educator will be to help families become independent and competent problem solvers.

Families of handicapped children for years have been demonsrating the capacity to deal with a variety of stressful events associated with their child's handicap. They also have identified positive contributions and strengths that result from living with a handicapped family member. The major goal for special educators is to use these strengths as a starting point for helping families negotiate adaptations associated with the handicapped family member over time.

\section{CONCLUSION}

New approaches to conceptualizing families, drawn from family sociologists and family therapists, have exciting implications for special educators who work with families. A major contribution is that much needed theoretical frameworks are now available to guide the development and implementation of intervention efforts. This holds promise that the elusive individualized approach can be realized with families.

The task ahead is to continue to translate theories into practical, working intervention models that can be implemented and evaluated with existing resources. To accomplish this, inservice and preservice training for special educators must incorporate knowledge and skill in content areas not traditionally associated with special education curricula. In addition, the collaboration between special educators and professionals from other disciplines that is taking place at the academic level must be encouraged among policy makers, administrators, and direct service providers. For family-focused intervention to be successful, those working directly with families must be supported by policy, training, and administrative procedures in their efforts to function as case managers. This entails helping families 
problem-solve and adapt in functional ways to the events associated over time with living with a handicapped family member.

\section{REFERENCES}

Aponte, H. (1985). The negotiation of values in therapy. Family Process, 24, 323-338.

Bailey, D. (in press). Preparing early interventionists to work with families: Focus on collaborative goal-setting. Topics in Early Childhood Special Education.

Bailey, D., Simeonsson, R., Winton, P., Huntington, G., Comfort, M., Isbell, P., O'Donnell, K., \& Helm, J. (1986a). Family-focused intervention: A functional model for planning, implementing and evaluating individual family services in early intervention. Journal of the Division for Early Childhood, 10, 156-171.

Bailey, D., Simeonsson, R., Winton, P., Huntington, G., Comfort, M., Isbell, P., O'Donnell, K., \& Helm, J. (1986b). A model for family-focused intervention. Training professionals to interact with families. [Monograph 2]. (Available from the Parent/Family Support Series, University of Idaho, Moscow, ID 83843)

Baker, B. (1984). Intervention with families with young, severely handicapped children. In J. Blacher (Ed.), Severely handicapped children and their families: Research in review (pp. 319-375). New York: Academic Press.

Becker, L., Bender, N., \& Kawabe, K. (1980). Exceptional parents: A survey of programs, services and needs. Academic Therapy, 15, 523538.

Berger M. (1986). Contributions of family therapy to the development of early childhood special education services that enhance individual and family development. Training professionals to interact with families [Monograph 2]. (Available from the Parent/Family Support Series, University of Idaho, Moscow, ID 83843)

Bernheimer, L., Young, M., \& Winton P. (1983). Stress over time: Parents with handicapped children. Journal of Developmental \& Behavioral Pediatrics, 14(3), 177-181.

Blair-Thomas, L., Wilson, T., \& Clark-Guida, J. (1985). Project ENTRANS: Model for transition of preschool handicapped children into public school. Monmouth: Oregon State System for Higher Education, Teaching Research Division.

Boss, P., \& Greenberg, J. (1984). Family boundary ambiguity: A new variable in family stress theory. Family Process, 23, 535-546.

Bronfenbrenner, U. (1976). The experimental ecology of education. Educational Researcher, 5, 5-15.

Bronfenbrenner, U. (1977). Toward an experimental ecology of human development. American Psychologist, 32, 513-531.

Cadman, D., Shurvell, B., Davies, P., \& Bradfield, S. (1984). Compliance in the community with consultants' recommendations for developmentally handicapped children. Developmental Medicine \& Child Neurology, 26, 40-46.

Cirillo, S., \& Sorrentino, A. (1986). Handicap and rehabilitation: Two types of information upsetting family organization. Family Process, 25, 283-292.

Doernberg, N. (1978). Some negative effects on family integrations of health and educational services for young handicapped children. $R e$ habilitation Literature, 39, 107-110.

Foster, M., \& Berger, M. (1979). Structural family therapy: Application in programs for preschool handicapped children. Journal of the Division for Early Childhood, 1, 52-58.

Foster, M., Berger, M., \& McLean, M. (1981). Rethinking a good idea: A reassessment of parent involvement. Topics in Early Childhood Special Education, 1, 55-65.

Fowler, S., \& Turnbull, A. (1984). Planning school transitions: Family and professional collaboration. Lawrence, KS: University of Kansas. (HCEEP Model Demonstration Project Grant available from authors, Bureau of Child Research, University of Kansas, Lawrence, KS 66044)

Gabel, H., \& Kotsch, L. (1981). Extended families and young handicapped children. Topics in Early Childhood Special Education, 1(3), 29-36.

Gallagher, J., Cross, A., \& Scharfman, W. (1981). Parental adaptation to a young handicapped child: The father's role. Journal of the Division for Early Childhood, 3, 3-14.

Gallagher, J., Maddox, M., \& Edgar, E. (1984). Early childhood interagency transition model. Bellevue, WA: Edmark.

Gallagher, J., Scharfman, W., \& Bristol, M. (1984). The division of responsibilities in families with preschool handicapped and nonhandicapped children. Journal of the Division for Early Childhood, 8, 3-11.

Goldenberg, I., \& Goldenberg, H. (1980). Family therapy: An overview. Monterey, CA: Brooks/Cole.

Haley, J. (1973). Uncommon therapy. New York: Horton.

Haley, J. (1980). Leaving home. New York: McGraw-Hill.

Hansen, D., \& Johnson, V. (1979). Rethinking family stress theory: Definitional aspects. In W. Burr, R. Hill, F. Hye, \& I. Reiss (Eds.), Contemporary theories about the family. Vol. 1: Research-based theories (pp. 582-603). New York: Free Press.

Hill, R. (1958). Social stresses on the family. Social Casework, 39, 139150.

Hoffman, L. , \& Manis, J. (1978). Influences of children on marital interaction and parental satisfactions and dissatisfactions. In R. Lerner \& G. Spanier (Eds.), Child influences on marital and family interaction: A life-span perspective (pp. 165-212). New York: Academic Press.

Isbell, L. (1983). Your child, education, the law and how to stand up to it all. In T. Dougan, L. Isbell, \& P. Vyas (Eds.), We have been there: A guidebook for parents of people with mental retardation (pp. 75-82). Nashville, TN: Abingdon Press.

Kaiser, C., \& Hayden, A. (1984). Clinical research and policy issues in parenting severely handicapped infants. In J. Blacher (Ed.), Severely handicapped young children and their families: Research in review (pp. 275-317). New York: Academic Press.

Karnes, M., \& Zehrbach, R. (1975, May). Matching families and services. Exceptional Children, 545-549.

Kazak, A. (1986). Families with physically handicapped children: Social ecology and family systems. Family Process, 25, 265-281.

Kazak, A., \& Marvin, R. (1984). Differences, difficulties and adaptation: Stress and social networks in families with a handicapped child. Family Relations, 33, 67-77.

Klein, D., \& Ross, A. (1958). Kindergarten entry: A study of role transition. In M. Krugman (Ed.), Orthopsychiatry and the school (pp. 6069). New York: American Orthopsychiatric Association.

Kopper-Roland, B. (1986). Families with a handicapped child. Training professionals to interact with families [Monograph 2]. (Available from Parent/Family Support Series, University of Idaho, Moscow, ID 83843)

Lamb, D. (1986). Early childhood special education and the family with a handicapped child. Training professionals to interact with families [Monograph 2]. (Available from the Parent/Family Support Network Series, University of Idaho, Moscow, ID 83843)

Latham, G., \& Locke, E. (1979). Goal-setting: A motivational technique that works. Organizational Dynamics, 45-54.

McCubbin, H., Cauble, A., \& Patterson, J. (1982). Family stress, coping and social support. Springfield, IL: Charles C Thomas.

McCubbin, H., \& Figley, C. (1983). Bridging normative and catastrophic family stress. In H. McCubbin \& C. Figley (Eds.), Stress and the family. Vol. 1: Coping with normative transitions (pp. 218-228). New York: Brunner/Mazel.

McCubbin, H., \& Patterson, J. (1983). Family transitions: Adaptation to stress. In H. McCubbin \& C. Figley (Eds.), Stress and the family. Vol. 1: Coping with normative transitions (pp. 5-25). New York: Brunner/Mazel. 
Minuchin, P. (1985). Families and individual development: Provocations from the field of family therapy. Child Development, 56, 289-302.

Olson, D., McCubbin, H., Barnes, H., Larsen, H., Muxen, M., \& Wilson, M. (1983). Families: What makes them work. Beverly Hills: Sage Publications.

Olson, J., \& Kroth, R. (1986). Training early interventionists in the delicate art of delivering sensitive information. Training professionals to interact with families [Monograph 2]. (Available from the Parent/Family Support Network Series, University of Idaho, Moscow, ID 83843)

Parke, R. (1986). Fathers, families, and support systems: Their role in the development of at-risk and retarded infants and children. In J. Gallagher \& P. Vietze (Eds.), Families of handicapped persons (pp. 101-114). Baltimore: Paul H. Brookes.

Rollins, B., \& Galligan, R. (1978). The developing child and marital satisfaction of parents. In R. Lerner \& G. Spanier (Eds.), Child influences on marital and family interaction: A life-span perspective (pp. 71-102). New York: Academic Press.

Rosenberg, M., Reppucci, N., \& Linney, J. (1983). Issues in the implementation of human services programs: Examples from a parent training project for high-risk families. Analysis and Intervention in Developmental Disabilities, 3, 215-225.

Simeonsson, R., \& Bailey, D. (1986). Siblings of handicapped children. In G. Gallagher \& P. Vietze (Eds.), Families of handicapped persons (pp. 67-80). Baltimore: Paul H. Brookes.

Stoneman, Z., \& Brody, G. (1984). Research with families of severely handicapped children: Theoretical and methodological considerations. In J. Blacher (Ed.), Severely handicapped young children and their families: Research in reveiw (pp. 179-214). Orlando, FL: Academic Press.

Suelzle, M., \& Keenan, V. (1981). Changes in family support networks over the life cycle of mentally retarded persons. American Journal of Mental Deficiency, 86, 267-274.

Turnbull, A., \& Brotherson, M. (1984, April). Assisting parents in future planning. Paper presented at the Council for Exceptional Children Annual Convention, Washington, DC.

Turnbull, A., Brotherson, M., Bruininks, G., Benson, H., Houghton, J., Roeder-Gorden, C., \& Summers, J. (1984). How to plan for my child's adult future: A three-part process to future planning. Lawrence: University of Kansas, Bureau of Child Research.

Turnbull, A., Summers, J., \& Brotherson, M. Family life cycle. In J. Gallagher \& P. Vietze (Ed.), Families of handicapped persons (pp. 45-65). Baltimore: Paul H. Brookes.

Turnbull, A., \& Turnbull, R. (1986). Families, professionals, and exceptionality: A special partnership. Columbus, $\mathrm{OH}$ : Charles E. Merrill.

Turnbull, H., \& Turnbull, A. (1982). Parent involvement: A critique. Mental Retardation, 20(3), 115-122.

Turnbull, A., \& Winton, P. (1984). Parent involvement policy and practice: Current research and implications for families with young, severely handicapped children. In J. Blacher (Ed.), Severely handicapped young children and their families: Research in review (pp. 377-397). New York: Academic Press.

Wikler, L. (1981). Chronic stresses of families of mentally retarded children. Family Relations, 30, 281-288.

Winton, P. (1986). The developmentally delayed child within the family context. In B. Keogh (Ed.), Advances in special education. Vol. 5: Developmental problems in infancy and the preschool years (pp. 219255). Greenwich, CT: JAI Press.

Winton, P., \& Turnbull, A. (1981). Parent involvement as viewed by parents of preschool handicapped children. Topics in Early Childhood Special Education, 1(3), 11-19.

Winton, P., Turnbull, A., \& Blacher, J. (1984). Selecting a preschool: A guide for parents of handicapped children. Austin, TX: Pro-Ed.

Wright, J., Granger, R., \& Sameroff, A. (1984). Parental acceptance and developmental handicap. In J. Blacher (Ed.), Severely handicapped young children and their families: Research in review (pp. 51-90). New York: Academic Press. 